Original Research

\title{
Testing the in situ Bulk Density of Mining Waste Stored in Dumping Grounds
}

\author{
Zenon Różański $^{1 *}$, Janusz Konior ${ }^{1}$, Leszek Balcarczyk ${ }^{2}$ \\ ${ }^{1}$ Silesian University of Technology, Faculty of Mining and Geology, Gliwice, Poland \\ ${ }^{2}$ POI Format Sp. j., Gliwice, Poland
}

Received: 24 October 2017

Accepted: 28 January 2018

\begin{abstract}
More than 200 dumps serving the disposal of waste produced by hard coal mines are situated in the Upper Silesian region. The material found in the dumps is mainly coal mining waste (i.e., overburden rocks obtained in the production and processing of hard coal). Volumetric and bulk densities are important physical parameters when it comes to recording the amount of waste disposed at the dumps. A possibility of determining this parameter during field studies was analysed. The method applied consisted of excavations performed in dump areas, weighing the excavated material and a precise determination of the volume of a selected space. A study carried out in this way allowed for testing a much larger sample, as the mass of the sample was only limited by the carrying capacity of the vehicle transporting the material to be weighed using industrial-grade scales. This had a positive impact on the accuracy of determining density. The precise determination of density was achieved by using the photogrammetric method, which guaranteed high accuracy. Two alternative photogrammetric techniques were used to ensure the control of calculations, i.e., close range terrestrial photogrammetry and low-altitude photogrammetry using unmanned aerial vehicles. Photographic equipment with high-resolution matrices was used. The processing of photographic documentation was conducted using professional software: Pix4d Mapper and AutoCad Civil 3D. Based on the mass and volume results obtained using the method described above, the bulk density of three coal mining waste samples was obtained for the actual conditions of the dump. The in-situ testing allowed us to consider the actual density of the waste material found in the dump.
\end{abstract}

Keywords: coal waste, dumping grounds, bulk density, photogrammetry, in situ

\section{Introduction}

One of the methods for utilizing industrial waste is to dispose of them in dumping grounds. In Upper Silesia, the predominant part of industrial wastes is

*e-mail: zenon.rozanski@polsl.pl constituted by coal mining wastes resulting from the excavation and processing of hard coal. According to the inventory conducted by Warcholik et al. [1], there are 220 facilities at which mining wastes were disposed of located in the Upper Silesian Coal Basin. The high costs of underground exploitation and the protection of natural mineral resources has caused these dumps to become increasingly interesting to investors, and they are often 
treated as anthropogenic secondary deposits excavated to recover coal and aggregates [2-3]. The physical and chemical properties of the excavated material are significant in view of the applied recovery technologies, the management of the wastes, and the environmental impact. The necessity to keep a record of the excavated material is also significant in that respect. Density is a physical parameter necessary to determine the mass of the material that is to be or was excavated. As for hard coal, reliable estimates of density are essential in order to value and quantify reserves and resources, calculate stripping ratios, estimate recovery, and in some cases determine royalty or tax payments. Even small errors in density estimates can add or remove many tons of reserves, and discrepancies may be difficult to catch before production begins [4].

Bulk density is the mass of a unit volume of bulk aggregate material in which the volume includes the volume of the individual particles and the volume of the voids between the particles [5]. In the SI system, $\mathrm{kg} / \mathrm{m}^{3}$ or $\mathrm{Mg} / \mathrm{m}^{3}$ is used as the unit of bulk density.

Sampling of soil for laboratory tests should be conducted in such a way as to obtain intact and representative samples as far as possible. The applied methods of determining the volumetric or bulk densities consist in acquiring small samples of material that are subsequently tested in laboratory conditions. The recommended method in the standard $\mathrm{T} 19 \mathrm{M} / \mathrm{T}$ is applicable to aggregates not exceeding $125 \mathrm{~mm}$ in nominal maximum size [5]. However, the carbonaceous wastes contain larger grains in their composition [6].

In Poland, the method for determining bulk density was described in the PN-B-04481:1988 Polish Standard [7]. According to the standard, bulk density testing depends on the soil properties and the dimensions of the delivered sample and may be conducted using one of the following methods:

- Hydrostatic lift in organic liquids.

- Hydrostatic lift of water.

- By measurement of sample volume using mercury lift.

- Using a ring with a specified volume.

- Using a cylinder with a specified volume.

The PN-B_04481:1988 standard was withdrawn in 2015 and was not replaced with another standard.

Information regarding methods for determining bulk density may be found in the PN-EN 1997-2:2009 Polish Standard [8], chapter 5: "Laboratory tests of soils and rocks." The standard does not, however, provide methods for determining bulk density by referring to the procedures, mode of conduct, and the assessment of results in the currently binding ISO 17892-2:2014 European Standard [9].

In line with this standard, the following methods may be used when determining bulk density:

- Linear measurement method.

- Immersion in fluid method.

- Fluid displacement method.
The linear measurement method consists of acquiring the sample, weighing it within an accuracy of $0.01 \mathrm{~g}$, and determining its volume by measuring its dimensions with an accuracy of $0.1 \mathrm{~mm}$. Bulk density is calculated using formula (1)

$$
\rho=\frac{m}{V}
$$

...where $\rho$ is bulk density in $\mathrm{Mg} / \mathrm{m}^{3}, m$ is mass of the sample in $\mathrm{Mg}$, and $V$ is volume of the sample in $\mathrm{m}^{3}$.

The immersion in fluid method consists in immersing the sample in a container that is completely filled with water suspended on scales using a frame and repeated weighing of the sample. In that method, the sample must be properly prepared. Surface voids should be filled with an insoluble material, and subsequently the sample must be covered with melted paraffin by means of repeated immersion. The volume of the sample is determined using formula (2):

$$
V=\frac{m_{w}-m_{g}}{\rho_{w}}-\frac{m_{w}-m_{t}}{\rho_{p}}
$$

...where $m_{w}$ is mass of the sample and the paraffin coating in $\mathrm{Mg}, m_{g}$ is mass of the sample and the paraffin coating immersed in water in $\mathrm{Mg}, m_{t}$ is mass of the sample in natural state in $\mathrm{Mg}, \rho_{p}$ is paraffin density in $\mathrm{Mg} / \mathrm{m}^{3}$, and $\rho_{w}$ is water density in $\mathrm{Mg} / \mathrm{m}^{3}$.

After determining the volume of the sample, the bulk density is determined using Eq. (1). In the fluid displacement method the test is conducted in a metal vessel equipped with a siphon. The vessel is filled with liquid up to a level above the siphon. A smaller vessel is placed beneath the siphon in order to collect the liquid. Before the measurement, the vessel for collecting the excess liquid should be weighed within $0.1 \mathrm{~g}$ accuracy and the sample should be prepared in a manner similar to that used in the water immersion method. The tested sample should then be fully immersed in the fluid and the valve of the siphon should be opened. In that way, the excess fluid should flow to the collecting vessel. In the fluid displacement method, the volume of the sample is determined based on formula (3):

$$
V=\frac{m_{2}-m_{1}}{\rho_{t}}-\frac{m_{w}-m_{t}}{\rho_{p}}
$$

...where $m_{1}$ is mass of the collecting vessel in $\mathrm{Mg}, m_{2}$ is mass of the collecting vessel and the fluid in $\mathrm{Mg}, m_{w}$ is mass of the sample and the paraffin coating in $\mathrm{Mg}, m_{t}$ is mass of the sample in natural state in $\mathrm{Mg}, \rho_{t}$ is fluid density, $\mathrm{Mg} / \mathrm{m}^{3}$, and $\rho_{p}$ is paraffin density in $\mathrm{Mg} / \mathrm{m}^{3}$.

After determining the volume of the sample, the bulk density is determined using formula (1).

The methods of laboratory testing applied in determining the density of the material found at dumping grounds do not give consideration to its 
natural densification resulting from long-term deposition. The purpose of this article is to present in situ methods that allow us to determine the bulk density of the waste material while giving consideration to the densification resulting from the long-term deposition in specified conditions and the effects of local physical and chemical factors. Bulk density of coal wastes stored at dumping grounds can be on a wide range. It depends on density of particular minestones and porosity. Mineralogical composition are important - especially coal content, grain composition, moisture content, and storage time. In different countries bulk density varies from 0.61 to $2.14 \mathrm{Mg} / \mathrm{m}^{3}$ [6].

In order to determine the actual density of coal wastes deposited on a dumping ground, a different method was used from those described in the standards. The in situ study involved the collection of large waste samples (approx. $20 \mathrm{Mg}$ ) by means of excavation and determining their mass after that. An industrial weight was used due to the size of the samples transported with a dumper truck. The up-to-date measuring techniques based on modern 3D image acquisition methods are currently used to determine the volume of different types of objects. The volume of excavations was determined during the study with the application of the photogrammetry method, which is becoming increasingly widespread in various fields. Due to the technological development of photography equipment, this method is characterised by high accuracy [10-12]. Therefore, it has been widely used in various branches of science and industry, including geometrical reproduction of various objects in 3D, mapping, inventory of areas, volume determination, slope landslide testing, and 3D documentation in archaeology, etc. [13-17].

\section{In situ Testing Method}

The study was conducted at the Przezchlebie central dumping ground located in the Upper Silesian Coal Basin, approximately $12 \mathrm{~km}$ from the city of Gliwice. It is a dump that was formerly used for the disposal of mining wastes from over a dozen coalmines operating in Gliwice, Zabrze, Bytom, Ruda Śląska, and in Suszec. Due to a slight variation in terms of the geological structures of the rock mass in the areas of the coal mines (i.e., the thickness of the seams, types of overburden rocks, and rocks beneath the seam), as well as varying efficiency of the coal dressing processes, the material disposed of at the dump is highly heterogeneous. Besides mining wastes, the dump also served the disposal of ash produced mostly by the Rybnik power plant.

Determining the density of coal mining wastes comes down to the determination of two parameters of the tested sample: mass and volume. Measuring the mass and volume in-situ conditions is a reliable assessment of the actual value of density. The transfer of the sample and conducting laboratory testing do not ensure the maintenance of the natural densification level.
Due to the above, the study of the density of the waste material comprised the following stages:

1) Selecting three locations in the dump region to conduct the study:

- excavation No 1 in the eastern region.

- $\quad$ excavation No 2 in the central region.

- $\quad$ excavation No 3 in the western region.

2) Performance of excavations with a volume of approximately $10 \mathrm{~m}^{3}$ in the selected locations after prior removal of the overburden.

3) Transport of the material to calibrated scales and the measurement of the mass after a prior taring of the transportation vehicle (four-axle dumper with a load capacity of $18-20 \mathrm{Mg}$ ).

4) Measuring the volume of the excavations using two types of photogrammetry: close range terrestrial photogrammetry and low-altitude photogrammetry using drones.

5) Computer processing of the results of photogrammetry and the calculation of the volume of excavations.

6) Determining density based on the dependence (Eq.4):

$$
\rho=\frac{m}{V_{e}}
$$

...where $m$ is mass of the sample (mass of the waste material from the excavation) in $\mathrm{Mg}$ and $V_{e}$ is volume of the excavation in $\mathrm{m}^{3}$.

\section{Determining the Mass of Samples}

In the selected locations, a $1 \mathrm{~m}$ layer of overburden was removed using an excavator. Subsequently, the tested waste material was excavated and loaded onto the dumper. The sample characterized by the mass limited by the vehicle's carrying capacity was then transported to the vehicle scales, where the mass of the empty vehicle was previously measured $(14300 \mathrm{~kg})$. The net mass of the samples from individual excavations was determined based on the difference between the net and gross mass of the vehicle. The scales were characterised by accuracy class III.

\section{Determining the Volume of Excavations}

Two alternative techniques were taken into account to determine the volume: 3D laser scanning and photogrammetry. Both methods are characterized by sufficient accuracy. However, they differ in terms of data collection methods $[15,18]$ :

- 3D laser scanning (Light Direction and Ranging LiDAR) - a method allowing for directly obtaining a point cloud with correct geometry and dimensions through measurement involving a laser beam pulsing at high frequency. The accuracy is mostly dependent on the equipment used for the measurement (from approximately $1 \mathrm{~mm}$ to $2 \mathrm{~cm}$ ) and the distance from the measured object. The time required to conduct the measurement from one position is from more 
than a dozen to several dozen minutes, depending on the pre-set scanning accuracy.

- Photogrammetry - close range terrestrial photogrammetry or low-altitude aerial photogrammetry using non-metric photographs. The technology consists in processing digital photographs to obtain a point cloud. Appropriate algorithms in the software seek for key points in each of the photographs. Subsequently, sets of points are matched in neighbouring photographs that were earlier performed with a sufficiently high coverage rate (approximately 60-80\%). This allows for a precise determination of the centre of perspective in each of the photographs and then for the calculation of the coordinates of local points. Because the obtained point cloud is not characterized by an appropriate scale, the cloud must be adjusted to the measured field points or scaling objects with known length. The accuracy is mostly dependent on the type of the measured object (natural objects with a highly varied texture are well-mapped, while artificial objects with reflexive and uniform textures pose a difficulty), the resolution of the camera and the distance from the measured object.

The photogrammetric method was selected due to the necessity to conduct efficient measurements in three distant locations after removing the top layer of the material and excavating the material in consideration.

\section{Preparing the Excavation Area}

5 points marked on A4 sheets were distributed around each of the excavations. Each of the points was measured using a GPS receiver in 30 observation epochs. In the area covered by the photos, 5 survey pegs with a marked length of $60 \mathrm{~cm}$ were also distributed for control of the developed point cloud or its possible scaling in the case of insufficient accuracy of the measured points. The method of preparing the area was presented in Fig. 1.

\section{Photographing}

Two alternative photogrammetric techniques were used to ensure the control of calculations, i.e., closerange terrestrial photogrammetry and low-altitude photogrammetry using drones (unmanned aerial vehicles, or UAVs). The following equipment was used: - Sony A7R 36 Mpix camera

Between 30 to 50 high-resolution terrestrial photographs were taken for each of the excavations for the initial surface (after removing the top layer of the material) and after performing the excavation from which the material to be weighed was acquired. The photographs were taken from locations surrounding the excavation in a manner ensuring an appropriately high coverage of the neighbouring photographs and the visibility of the marked points. Due to the large depth of the excavation at a low diameter, there was a risk that the bottom of the excavation would not be correctly mapped. For this reason, a drone was also used. Such a situation occurred in the case of excavation No. 2, which is why the calculations were made based on the drone photographs. In the case of excavation Nos. 1 and 3, the photos taken with a Sony A7R camera were used. - DJI Phantom 2 Vision+ Drone with a 14 Mpix camera.

Between 20 to 55 photos were taken using a Pix $4 d$ Mapper mobile application. The free flight option was used with the shutter release set to $2 \mathrm{~m}$ in the horizontal plane and to $1 \mathrm{~m}$ in the vertical plane.

\section{Merging and Introducing the Photographs into the Coordinate System}

The first stage of processing the photographs was merging in Pix4d Mapper software using automatic algorithms seeking the keypoints in the photographs and performing the matching. As a result, a low-density point cloud without a fixed scale was developed.

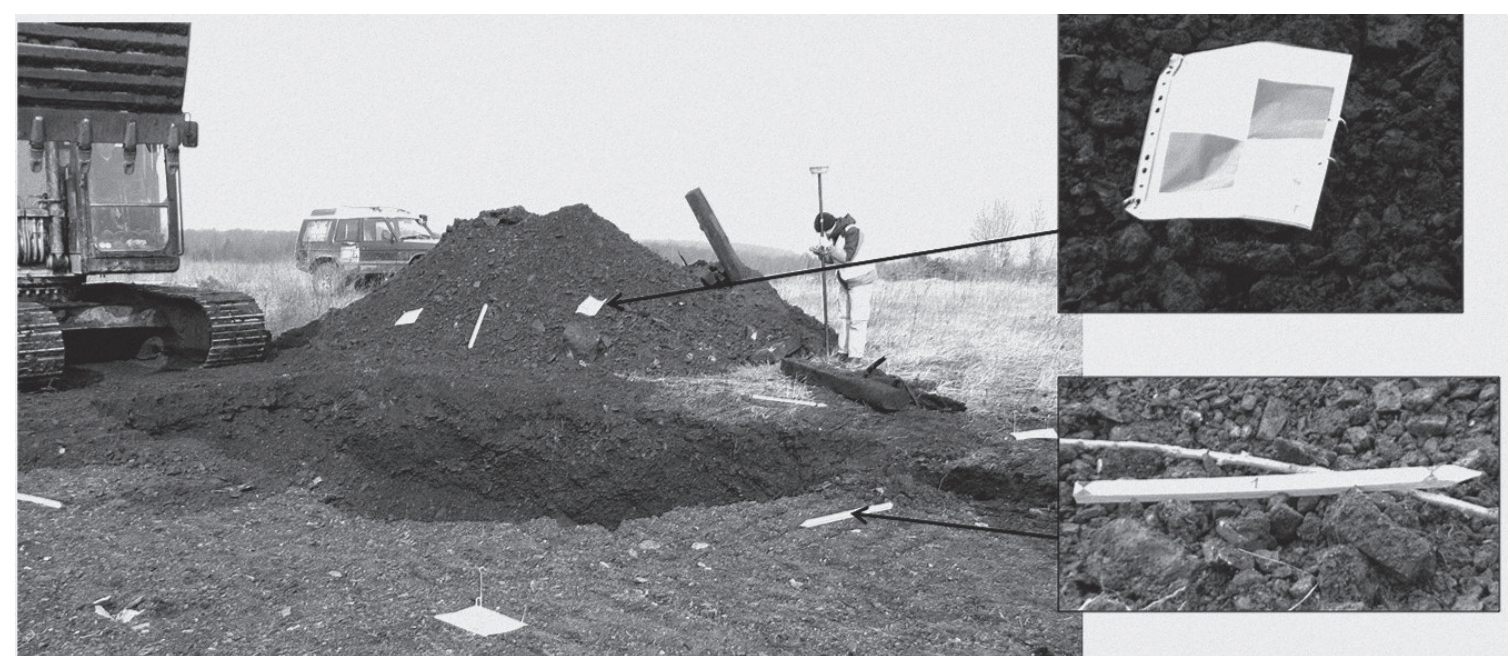

Fig. 1. The prepared excavation after the removal of the top layer of the material. 


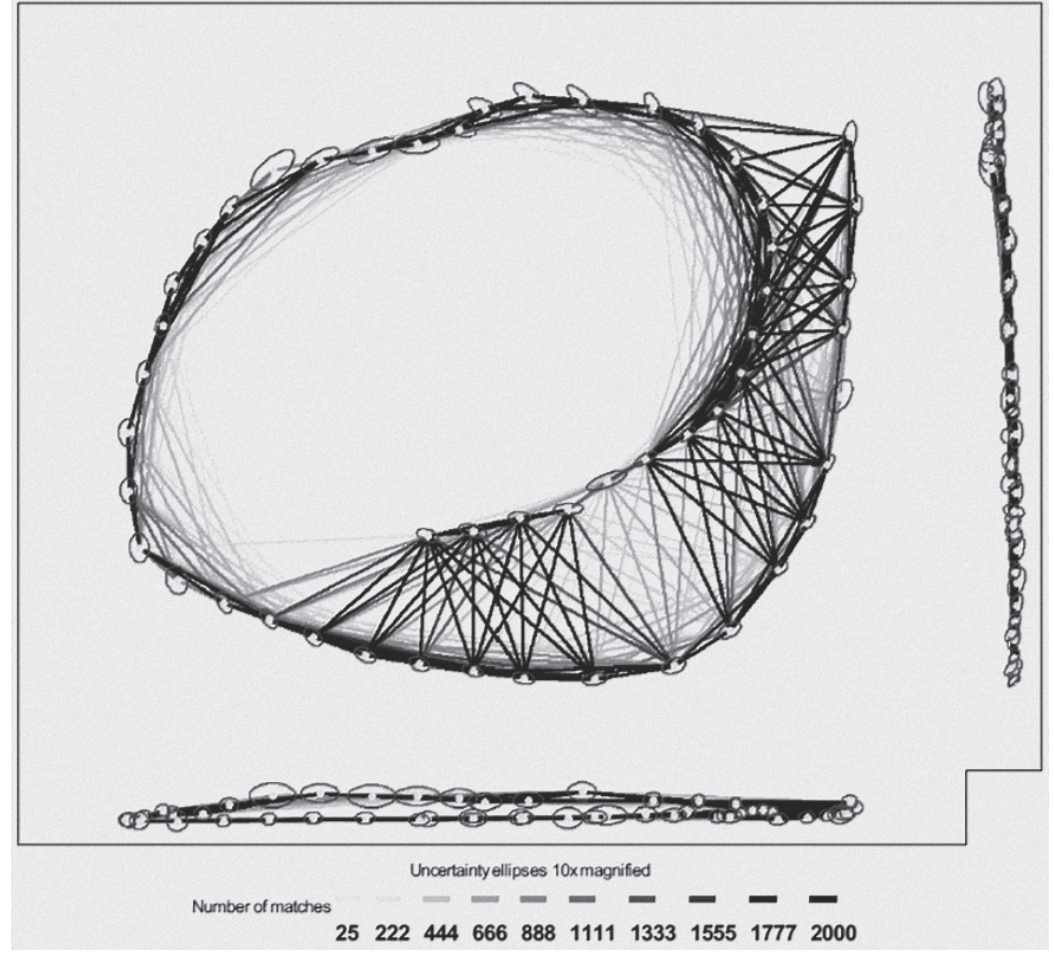

Fig. 2. Image generated from the report presenting the interconnected merging of the photos.

After merging the photos (Fig. 2), the cloud was matched to the measured points. As a result of the adjustment, an average RMS error was obtained at a level of approximately $1 \mathrm{~cm}$ for all matched clouds. It must be noted that this is the model adjustment error and not relative accuracy, which is several times higher. The error is mostly caused by the accuracy of the GPS receiver.

\section{Point Cloud Densification}

The densification of the adjusted point cloud conducted in the Pix4d Mapper program constitutes another stage. As a result, sets of several million points were obtained for each of the models. Based on the point cloud, a uniform model was also prepared - a 3D mesh with a texture generated using the Poisson algorithm. Fig. 3 presents views of the densified point cloud and the 3D mesh. Due to the high resolution of the cloud, the difference from the 3D mesh is visible mostly on the edges, where the coverage of the photos was lower.

\section{Reading in the Point Cloud, Creating the Triangular Network, and Calculating the Volume}

The densified point clouds from individual excavations were imported to AutoCAD Civil 3D software, and triangulated irregular networks (TINs) were sketched based upon them. Due to the high densification of points, the density was reduced in a manner allowing for the efficient generation of the 3D surfaces comprising approximately 50,000 triangles.
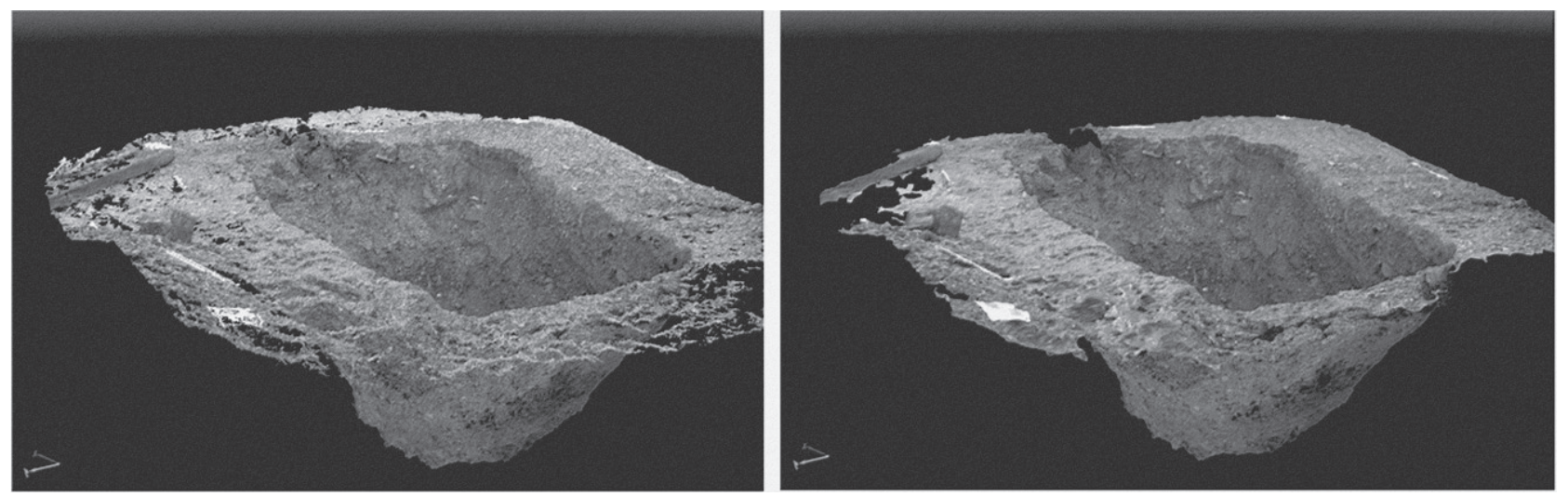

Fig. 3. Point cloud (left) and 3D mesh (right) of one of the excavations. 
6 surfaces were created: one base surface (initial after the removal of the top layer of the material) and one reference surface (bottom of the excavation) for each of the three excavations.

After creating the base and reference surface pairs, the so-called volume surface, which is a comparison of both TIN models, was generated. The information on the volume of the body was acquired from the software and a visualization of height differences between the base and reference surfaces was sketched.

\section{Results of the Study}

Mass of the Samples

The mass of the samples was different in the case of each of the excavations. The mass of the first sample

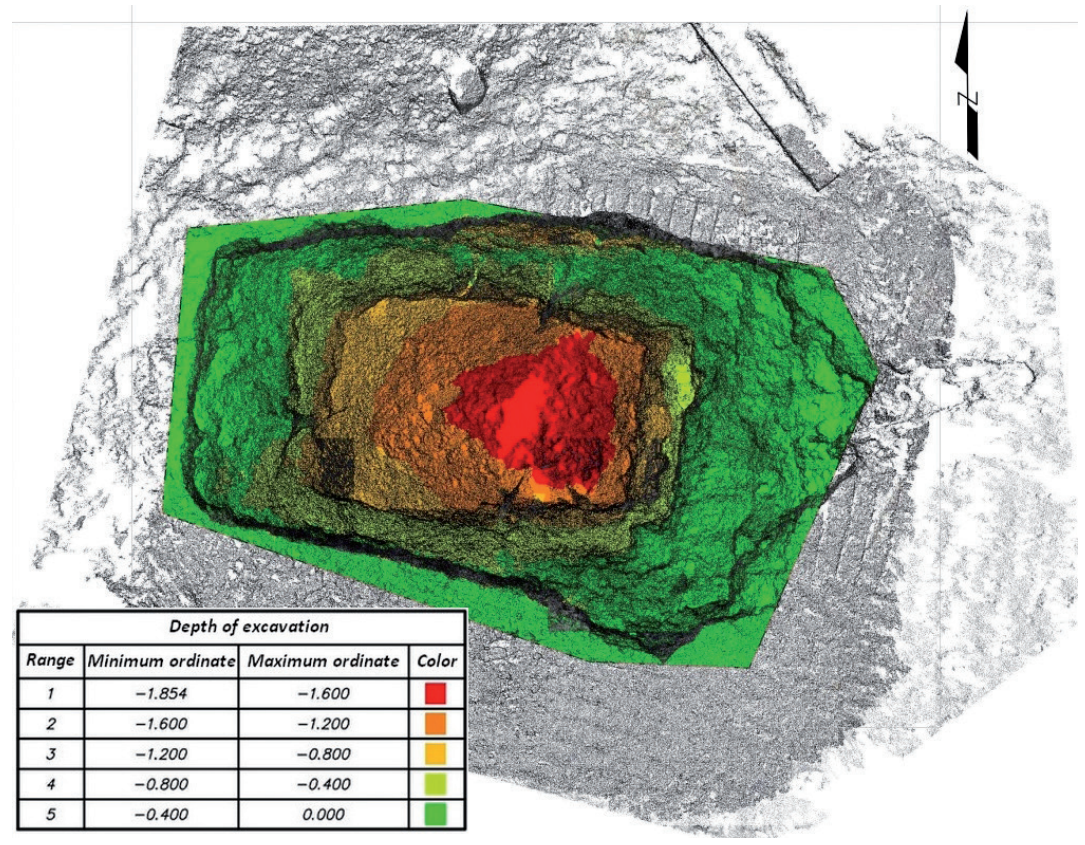

Fig. 4. Result of the volume calculation for the excavation No $1-12.69 \mathrm{~m}^{3}$.

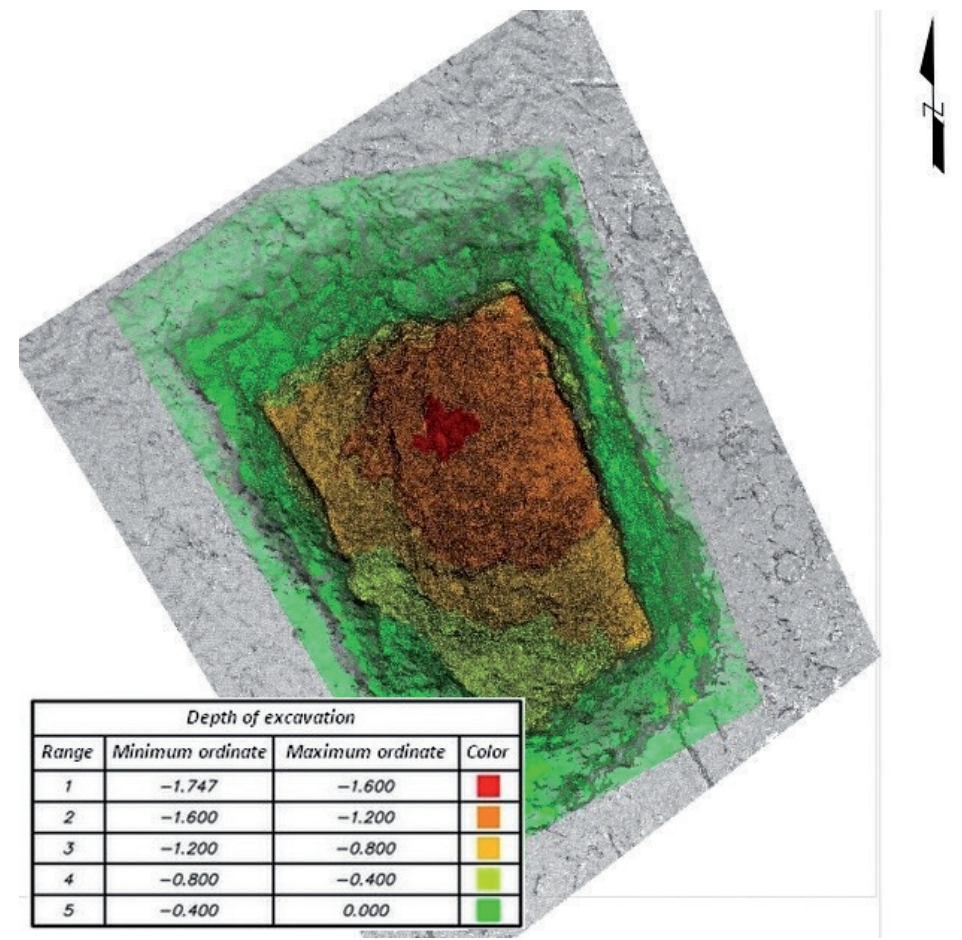

Fig. 5. Result of the volume calculation for the excavation No $2-9.76 \mathrm{~m}^{3}$. 


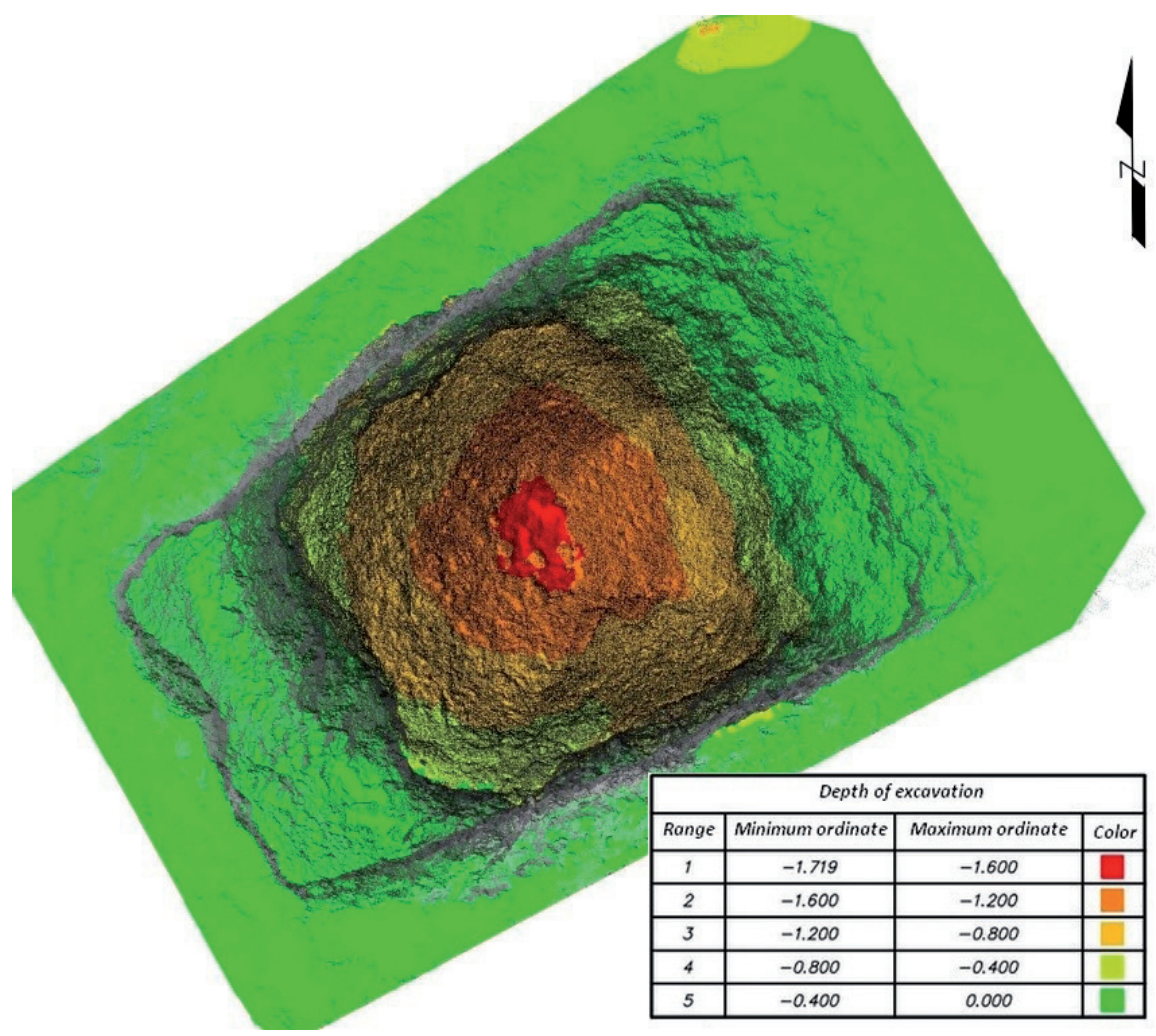

Fig. 6. Result of the volume calculation for the excavation No $3-10.54 \mathrm{~m}^{3}$.

slightly exceeded the load capacity of the transportation vehicle. The subsequent two samples were taken in smaller quantities. The masses of the samples were as follows:

- Excavation No. 1 sample - $21.900 \mathrm{Mg}$.

- Excavation No. 2 sample - $17.100 \mathrm{Mg}$.

- Excavation No. 3 sample - $17.300 \mathrm{Mg}$.

\section{Volume of the Samples}

The volume of the excavation determined using AutoCAD Civil $3 \mathrm{~d}$ software constitutes the difference between the area limited by the base surface and the reference surface. The results of the calculations were presented in Figs 4-6, in which a coloured visualisation of the differences in heights between the base and reference surfaces was also shown.

\section{Bulk Density}

A full list of the results of the measurements of mass and volume and the calculation of density is presented in Table 1 below. The results of measurements and calculations indicate a certain level of heterogeneity of the material, which stems from the differences in the densification of the material in different regions of the dump as well as composition, graining, and moisture content. All these factors result from the natural conditions occurring at the dump.

\section{Conclusions}

The methods used to determine the bulk density proposed in the standards do not allow for a precise

Table 1 . Density of coal mining wastes.

\begin{tabular}{|c|c|c|c|}
\hline \multirow{2}{*}{$\begin{array}{c}\text { Excavation } \\
\text { number }\end{array}$} & \begin{tabular}{c} 
Mass of the excavated material \\
\cline { 2 - 4 }
\end{tabular} & $\begin{array}{c}\text { Calculated volume of the excavation } \\
\mathrm{V}_{\mathrm{e}}\end{array}$ & $\begin{array}{c}\text { Density of the material } \\
\rho\end{array}$ \\
\hline 1 & $\mathrm{Mg}$ & $\mathrm{m}^{3}$ & $\mathrm{Mg} / \mathrm{m}^{3}$ \\
\hline 2 & 21.900 & 12.69 & 1.726 \\
\hline 3 & 17.100 & 9.76 & 1.752 \\
\hline & 17.300 & 10.54 & 1.641 \\
\hline
\end{tabular}


determination of the bulk density of a highly heterogeneous material such as coal mining wastes. Laboratory studies of coal mining wastes obtained at dumping grounds do not give consideration to their natural densification.

Acquiring large samples for testing (approximately $20 \mathrm{Mg}$ ) allows us to obtain more representative samples and to achieve a better average of the results. The use of the photogrammetry method (alternatively laser scanning) and the measurement of the volume of the acquisition point, and not the volume of an affected sample, allows us to give consideration to the natural densification of the material caused by long-term deposition.

The obtained volumetric density values for three samples collected from the Przezchlebie dumping ground amounted to: $1.726,1.752$, and $1.641 \mathrm{Mg} / \mathrm{m}^{3}$. The average value was $1.706 \mathrm{Mg} / \mathrm{m}^{3}$. In this case, this value was used for further calculations related to the mass of the exploited material on the basis of the volume of the actual mining pits. On the other hand, the obtained results constituted the basis for financial settlements between the company conducting the operation and the owner of the dumping ground.

The applied method of determining bulk density is relatively simple and does not require labour-intensive activities. An additional advantage is the low cost, both when it comes to determining the mass and volume of the samples collected, with high accuracy at the same time. The method may be applied for other rock wastes, aggregates, and materials characterised by low firmness and high variability in terms of graining and composition.

\section{Acknowledgements}

Our thanks to Mr. Justin Nnorom for proofreading the text.

\section{Conflict of Interest}

The authors declare no conflict of interest.

\section{References}

1. WARCHOLIK W., DOLNICKI P., GAWOR Ł. Possibilities of exploitation of secondary deposits (post mining dumping grounds) as an example of changes in extractive industry. Studies of the Industrial Geography Commission of the Polish Geographical Society, 27, 256, 2014 [In Polish].

2. GAWOR Ł. Coal mining waste dumps as secondary deposits-examples from the Upper Silesian Coal Basin and the Lublin Coal Basin. Geology, Geophysics and Environment, 40 (3), 285, 2014.
3. RÓŻAŃSKI Z., SUPONIK T., MATUSIAK P., KOWOL D., SZPYRKA J., MAZUREK M., WRONA P. Coal recovery from a coal waste dump. E3S Web of Conferences, 8, 01052. EDP Sciences, 2016.

4. ROBECK E., HUO D. A more accurate method for estimating in situ coal density and mineral matter from ash and specific energy determinations, International Journal of Coal Geology, 168, 237, 2016

5. AASHTO $\mathrm{T} 19 \mathrm{M} / \mathrm{T}$ 19-00, Standard Method of Test for Bulk Density ("Unit Weight") and Voids in Aggregate. American Association of State Highway and Transportation Officials Standard, 2004.

6. SKARŻYŃSKA K.M. Reuse of coal mining wastes in civil engineering-part 1: Properties of minestone. Waste Manag, 15 (1), 3, 1995.

7. PN-B-04481 Polish standard: Construction grounds - The tests of ground samples, Polish Committee for Standardization, Warsaw 1988 [In Polish].

8. PN-EN 1997-2 Polish Standard: Eurocode 7 - Geotechnical Design - Part 2: Ground investigation and testing, Polish Committee for Standardization, Warsaw 2009 [In Polish].

9. ISO 17892-2 European Standard: Geotechnical investigation and testing - Laboratory testing of soil - Part 2: Determination of bulk density. European Committee for Standardization, 2014.

10. LUHMANN T. Precision potential of photogrammetric $6 \mathrm{DOF}$ pose estimation with a single camera. ISPRS J Photogramm Remote Sens, 64 (3), 275, 2009.

11. LUHMANN T. Close range photogrammetry for industrial applications. ISPRS J Photogramm Remote Sens, 65 (6), 558, 2010.

12. ZHANG X., LI L., CHEN G., LYTTON R. A photogrammetry-based method to measure total and local volume changes of unsaturated soils during triaxial testing. Acta Geotechnica, 10 (1), 55, 2015.

13. OKA N. Application of photogrammetry to the field observation of failed slopes. Engineering Geology, 50 (1), $85,1998$.

14. HEYDUK A. Bulk density estimation using a 3-dimensional image acquisition and analysis system. E3S Web of Conferences 8, 01060, EDP Sciences, 2016.

15. KOLECKA N. Photo-based 3D scanning vs. laser scanning-Competitive data acquisition methods for digital terrain modelling of steep mountain slopes. International Archives of the Photogrammetry, Remote Sensing and Spatial Information Sciences, 38 (4), 2011.

16. LERMA J.L., NAVARRO S., CABRELLES M., VILLAVERDE V. Terrestrial laser scanning and close range photogrammetry for 3D archaeological documentation: the Upper Palaeolithic Cave of Parpalló as a case study. J Archaeol Sci, 37 (3), 499, 2010.

17. ESPOSITO G., MASTROROCCO, G. SALVINI, R., OLIVETI M., STARITA P. Application of UAV photogrammetry for the multi-temporal estimation of surface extent and volumetric excavation in the Sa Pigada Bianca open-pit mine, Sardinia, Italy. Environ Earth Sci, 76 (3), 103, 2017.

18. BALTSAVIAS E.P. A comparison between photogrammetry and laser scanning. ISPRS J Photogramm Remote Sens, 54 (2), 83, 1999. 